\title{
Protecting participants in health research: The South African Material Transfer Agreement
}

\author{
M Labuschaigne, ${ }^{1}$ BA (cum laude), BA Hons (cum laude), MA (cum laude), DLitt, LLB (cum laude), LLD; \\ A Dhai, ${ }^{2}$ MB ChB, FCOG, LLM, PG Dip (Int Res Ethics), PhD; S Mahomed, ${ }^{1}$ BCom, LLB, LLM, PhD; K Behrens, ${ }^{2}$ BA, MA, D Litt et Phil; \\ A Nienaber, ${ }^{3}$ BA Hons, LLB, LLM (cum laude), LLD; K Moodley, ${ }^{4}$ MB ChB, MFamMed (cum laude), MPhil (Applied Ethics) (cum laude), \\ FCFP (SA), DPhil, Executive MBA; P Cleaton-Jones, ${ }^{2} \mathrm{MB}$ BCh, PhD, DSc (Dent); A Olckers, ${ }^{5} \mathrm{NDip}$ Med Tech, BSc, MSc, PhD; \\ N Maepa, ${ }^{6}$ BA Law, LLB, LLM; C Penny, ${ }^{7}$ BSc Hons, PhD \\ ${ }^{1}$ Department of Jurisprudence, School of Law, University of South Africa, Pretoria, South Africa \\ ${ }^{2}$ Steve Biko Centre for Bioethics, Faculty of Health Sciences, University of the Witwatersrand, Johannesburg, South Africa \\ ${ }^{3}$ Department of Public Law, Faculty of Law, University of Pretoria, South Africa; and Faculty of Health Sciences Research Ethics Committee, \\ University of Pretoria, South Africa \\ ${ }^{4}$ Centre for Medical Ethics and Law, Department of Medicine, Faculty of Medicine and Health Sciences, Stellenbosch University, Cape Town, \\ South Africa \\ ${ }^{5}$ DNAbiotec (Pty) Ltd, Pretoria, South Africa \\ ${ }^{6}$ Legal Office, University of the Witwatersrand, Johannesburg, South Africa \\ ${ }^{7}$ Human Research Ethics Committee (Medical), University of the Witwatersrand, Johannesburg, South Africa; and Department of Internal \\ Medicine, Faculty of Health Sciences, University of the Witwatersrand, Johannesburg, South Africa
}

Corresponding author: M Labuschaigne (slabbmn@unisa.ac.za)

The need to transfer human biological materials (HBMs) across national boundaries has become increasingly important in view of increased biobank and commercial activities globally. In light of South Africa (SA)'s history of colonisation and racial discrimination, coupled with well-known instances of exploitation of research participants in the developing world, it is critical that the management of HBMs from and to other jurisdictions is explored and regulated. Material transfer agreements (MTAs) represent an important point of departure in such a process. This article explores the need for a uniform MTA in SA and discusses some aspects of the recently gazetted national MTA, which provides a framework that can serve as a safeguard for cross-border transfer of HBMs in the absence of the National Health Act's chapter 8 regulations in this regard.

S Afr Med J 2019;109(5):353-356. DOI:10.7196/SAMJ.2019.v109i5.13803

The need to transfer human biological materials (HBMs) across national boundaries has become increasingly important in the light of increased biobank and commercial activities globally. Biobank research provides for significant and accelerated improvements in the understanding of health, diseases, and the effectiveness, efficiency, safety and quality of preventive, diagnostic and therapeutic interventions. ${ }^{[1]}$ In view of South Africa (SA)'s history of colonisation and racial discrimination, coupled with well-known instances of exploitation of research participants in the developing world, it is critical that the management of HBMs from and to other jurisdictions is cautiously scrutinised and regulated. A generally accepted way in which this can be achieved is with the systematic use of material transfer agreements (MTAs). While in SA HBMs are governed by chapter 8 of the National Health Act 61 of 2003 (NHA), ${ }^{[2]}$ there are no regulations governing biobanks and the cross-border transfer of HBMs, except for those relating to applications for import and export permits. ${ }^{[3]}$

The purpose of MTAs is to facilitate the exchange of HBMs and associated data between researchers/institutions, as well as to safeguard the interests of research participants, researchers and their institutions. Conventionally, an MTA typically sets out the uses of the material, the quality of the material, terms and conditions under which the material may be used, third-party transfers, benefit-sharing mechanisms, and intellectual property rights and other legal and/or regulatory policies or guidelines that need to be considered. ${ }^{[4]}$ In SA, the Health Professions
Council of South Africa ${ }^{[5]}$ and the National Department of Health guidelines on Ethics in Health Research (National Ethical Guidelines) ${ }^{[6]}$ require the conclusion of MTAs before HBMs are transferred out of SA. The National Ethical Guidelines (section 3.5.2.3) in addition state that 'where data or materials are shared with researchers in other institutions, the recipient institution should agree to comply with the requirements of the donor institution', as well as with 'any additional requirements of the recipient institution'. The National Ethical Guidelines recommend that these inter-institutional sharing agreements are confirmed in writing.

The purpose of this article is to explore the need for a uniform MTA in SA and to discuss some aspects of the recently gazetted national MTA. ${ }^{[7]}$ The point of the article is not to address complex legal and philosophical debates relating to the transfer of HBMs, but to provide a factual analysis of the current situation with regard to HBMs in SA.

\section{Why a need for MTAs?}

Research using HBMs should have societal benefits and contribute to public health objectives. ${ }^{[1]}$ It was common practice for researchers to share research materials freely, as scientific research relies, inter alia, on the ability of researchers to replicate and test published research results. In the context of health research, such an exercise would require access to the relevant biological material and/or 
information derived therefrom. The increasing gap between basic research and commercial developments has led to more pronounced efforts to capitalise on novel research leading to, among others, new commercially viable genes, cell lines, reagents or antibodies, which in turn rely on access to HBMs and associated data. Genome and genetic resources are specifically targeted for public and private investment funding to enable further discovery of gene regulation or function. However, vexing questions have emerged, e.g. who will own or control these downstream discoveries, ${ }^{[8]}$ the type of consent for secondary use of HBMs, who will share the benefits resulting from these studies, how disputes are to be resolved should they arise, and the power imbalances in international collaborative research. In addition, the reality is that exploitation of research participants/donors in health research in SA does occur. Empirical evidence has confirmed that HBMs were leaving the country without export permits and MTAs during international collaborative research in both investigator-initiated and industry-driven clinical trials. ${ }^{[9]}$ Furthermore, the African context needs to be understood, including the fact that deep significance is attached to blood and HBMs by black African communities. ${ }^{[10,11]}$ Despite these concerns, MTAs that have standardly been used in SA so far have typically lacked ethical safeguards, do not address concerns specific to $\mathrm{SA}^{\left[{ }^{[12]}\right.}$ and have restricted protections in that they derive from strict legal principles only. This is not sufficient for SA settings. The evidence demonstrates that more needs to be done in order to effectively protect local donors and institutions when the cross-border transfer of HBMs is contemplated. ${ }^{[9,10,11,13]}$ Furthermore, the Protection of Personal Information Act 4 of 2013 (POPI) ${ }^{[14]}$ explicitly states that personal information may only be transferred to a foreign country if that country offers similar protections in respect of personal information and the transfers thereof, as envisaged by the Act. Currently no uniformity or standardisation exists as each institution chooses to utilise its own/sponsor-preferred MTA. For over a decade there have been calls by concerned parties, including meetings attended by some of the authors of this article and convened by the Department of Science and Technology, for a uniform MTA for SA that takes into consideration our ethical and sociocultural context.

Universities in SA are under increasing pressure to generate income from sources other than government subsidies. Many research institutions have technology transfer or research offices specifically dedicated to managing research grant applications and related matters. Applications for ethical clearance are routinely reviewed by health research ethics committees (HRECs) at these institutions. Researchers and students generally lack the relevant legal knowledge to enter into legal agreements and complete research ethics applications without assistance from either an HREC, a relevant technology transfer office (TTO) or a research office. This centralisation of contract services in a technology transfer or research services office is often criticised for leading to delays and conflicts between the interests of research participants, researchers and their institutions. ${ }^{[15]}$ Moreover, research offices or TTOs may struggle to balance conflicting mandates, e.g. to commercialise research at their institutions to achieve financial returns on investments and to promote the desired community-level sharing of materials, data ${ }^{[16]}$ and benefits.

\section{The SA National MTA}

In July 2018, the National Department of Health gazetted a Material Transfer Agreement of Human Biological Materials (SA MTA) ${ }^{[7]}$ for use in research or clinical trials under the auspices of HRECs as regulated by the NHA. The SA MTA is founded on the principles of justice, fairness and dignity, in line with the principles of the World
Medical Association's Declaration of Taipei on Ethical Considerations Regarding Health Databases and Biobanks ${ }^{[1]}$ and the Council for International Association of Medical Scientists guidelines, ${ }^{[17]}$ and in keeping with international best practices. Some aspects of the MTA are discussed below.

\section{The SA MTA as a framework}

The SA MTA ${ }^{[7]}$ is applicable when materials (HBMs and data) are transferred outside SA for health research purposes, which includes biobank research. The objective of the MTA is to set out a framework/ template within which the parties engage in the transfer, use and other processing of the materials. This means that the SA MTA provides guidance on specific ethicolegal principles that must be respected when cross-border transfer takes place. While the cover page to the SA MTA indicates that 'All the providers and recipients of the biological material for use in research or clinical trials under the auspices of the Health Research Ethics Committees shall use the Materials Transfer Agreement of human Biological Materials [sic]', clause 1 of the SA MTA explicitly states that the 'objective of this Agreement is to set out a framework within which the Parties will engage in the transfer, use and other processing of the Materials .... The intention of the SA MTA is therefore not to prescribe its use verbatim, but rather to serve as a uniform, national template.

\section{Parties to the SA MTA and the role of the HREC}

The SA MTA refers to an HREC (required by law to be registered with the SA National Health Research Ethics Council in terms of section 73 of the NHA), the Providing Institution (provider) and the Recipient Institution (recipient), as parties to the agreement.

It may be argued that the HREC is not a separate legal entity and hence is unable to enter into such an agreement. The question whether HRECs should be part of such agreements is best addressed by referring to the HREC's role and responsibility with regard to the review and approval of research protocols that require the transfer of HBMs. Firstly, HRECs are ideally situated within research institutions to provide the required oversight to ensure that the ethicolegal requirements of MTAs are complied with and adequately monitored, while also making sure that scientific progress is not stifled. Moreover, although there is no general legal duty of care recognised in SA, ${ }^{[18,19]}$ except when there is a special relationship between the duty-bearer and another person, such as doctor v. patient, parent v. child, teacher v. pupil or police officer v. citizen, such a special relationship exists between an HREC and a research participant. ${ }^{[20]}$ One of the main purposes of an HREC is to ensure that adequate protections are in place for research participants when health research is contemplated. Inversely and by analogy, it may be argued that an HREC owes research participants a reasonable duty of care and may hence be held liable for harm resulting to research participants through negligently conducted research, if such a committee failed to take the necessary reasonable steps to prevent reasonably foreseeable harm or injury to research participants. In the Canadian Supreme Court judgment of Weiss v. Solomon, ${ }^{[21]}$ the family of a research participant who suffered a cardiac arrest and died subsequent to an angiogram as part of a research study sued the principal investigator, the hospital and a physician who referred the deceased to the study. The court held the primary investigator and hospital liable. The liability against the hospital was based, in part, on the fact that the HREC of the hospital had approved the research protocol and the consent form that the court found to be deficient. An institution that has established an HREC will be vicariously liable for negligent conduct by its HRECs with regard to ethical reviews that caused foreseeable harm to a participant. ${ }^{[20]}$ 
SA, too, has seen litigation where the HREC is mentioned in proceedings after granting ethics approval to a pharmaceutical research project. In Venter $v$ Roche Products (Pty) $L t d,{ }^{[22]}$ a full bench of the Western Cape High Court considered whether the plaintiff, $\mathrm{Mr}$ Venter, was entitled to compensation for non-medical costs such as pain and suffering, loss of income and general damages, even though the HREC-reviewed informed consent document specifically excluded such claims. In this case, the High Court clearly placed responsibility for protecting the interests of research participants (such as whether and to what extent they receive compensation and whether this was in the participant informed consent documentation) squarely on the shoulders of the HREC: the HREC grants ethics approval in terms of section 73(2)(b) to 'protocol[s] [that] meet the ethical standards of that health research ethics committee'. It is possible to deduce that in the same way compensation for researchrelated injuries was regarded by the court as an ethical issue, so too in the future the existence and contents of an MTA will be regarded by the courts as ethically relevant. Therefore, HRECs will have to ensure that MTAs are in place and that they conform to the norms and standards set out in the NHA and the National Ethical Guidelines.

The HREC is directly involved in reviewing protocols, and is closest in proximity to the material transfer process (clause 6). The SA $\operatorname{MTA}^{[7]}$ (clause 6) includes provisions that speak directly to the ethical safeguards for HBMs and data, and HREC oversight is emphasised throughout the document. The HREC often becomes involved in negotiating and resolving disputes as a first point of reference for ethical concerns that may arise. It is to be noted that the Draft R\&D Blueprint MTA developed by the WHO for severe emergency disease with potential to create a public health emergency indicates that 'in some cases it may be desirable to include a suitable third party in MTAs to act as a neutral party to ensure negotiation in good faith and an unbiased implementation. ${ }^{[23]}$ An HREC should have no vested interest in the research process. It acts to protect and balance the interests of research participants and local researchers with scientific research pursuits, and hence it is submitted that it is well placed to sign off on the MTA.

\section{Custodianship and ownership}

The SA MTA ${ }^{[7]}$ (clause 3.3) stipulates that the providing institute is custodian of the materials. The concept of custodianship has been supported where HBMs are concerned. ${ }^{[24-26]}$ There have been incidents in the past where disputes arose between local researchers and institutions outside SA where these institutions claimed ownership of the materials and associated data after transfer took place, resulting in local researchers being unable to access the materials. ${ }^{[27]}$ In addition, there have been several recorded disputes with regard to ownership of HBMs outside SA. ${ }^{[28-36]}$ Allowing the providing institute to remain custodian of the materials allows for the caretaking obligation for materials, as well as the obligation to protect, guard and maintain, from initial collection to final distribution of research findings. It endorses key practices and operating principles for responsible oversight of materials collected for research and ensures transparency in research, fairness to research participants, and shared responsibility among all stakeholders involved in the research. ${ }^{[25]}$ According to the SA MTA ${ }^{[7]}$ donors remain owners of their materials. This is in line with the Regulations 180 (section 7) on the 'General control of human bodies, tissues, blood, blood products and gametes, ${ }^{[37]}$ which suggests that a donor's rights in his/her HBMs are not completely relinquished when HBMs are donated. The same Regulations make provision for the acquisition of exclusive rights in deceased bodies or human tissue, blood or gametes (donated in terms of the NHA and any of the regulations) by a person upon receipt of such bodies and tissue (section 26), provided that these bodies or tissue are used for the purposes for which they were donated. Although the purpose of a tissue donation need not be expressly stated, tissue may only be donated for the specific outlined purposes in the Regulations. Consequently, a tissue donor retains proprietary control over the directed donation in the sense that his/her tissue may not be used for other than the prescribed purposes. 'Exclusive rights' in this sense should hence not be equated with ownership per se. SA and African communities attach great importance to their blood and blood products. ${ }^{[10,38]}$ In accordance with our current ethicoregulatory framework, donors therefore retain certain controls over the use of their materials, even after informed consent has been obtained for their use. Donors can request the deletion or destruction of the data/HBMs and can withdraw from a research project or object to their materials being used, which all underscores the fact that the donors' ownership rights in their materials are not completely relinquished and that donorship for specific purposes in itself is not an unconditional contribution. This is also in accordance with the provisions of Condition 8 of POPI (section 23-25). ${ }^{[14]}$

\section{Benefits and benefit sharing}

Examples of benefits are provided in the SA MTA ${ }^{[7]}$ (clause 2.2) and include (but are not limited to) the sharing of information, use of research results, publication rights, the transfer of technology, and capacity building. It also provides for local researchers to benefit from joint publications by stipulating that publications need to be in line with internationally accepted ethical norms (clause 14). Historically, local research participants and local researchers received few to no benefits in exchange for their contributions to scientific discovery. ${ }^{[9]}$ While the SA MTA includes benefit sharing as a principle, it does not prescribe what the benefit should entail, or that benefit sharing must take place. It does, however, state that this should be discussed and negotiated prior to transfer.

\section{Secondary uses}

The SA MTA ${ }^{[7]}$ (clause 2.17) defines secondary uses as the use of the Materials for health research purposes other than the uses determined in the approved protocol. The justification for the approval of secondary uses by an HREC is that as secondary uses of materials are included in 'health research' as contemplated by section 1 of the NHA, and as all HRECs are required to review and approve all health research proposals and protocols, approval for secondary uses of material must be obtained from an HREC. Clause 10.3 of the SA MTA states that ' $[t]$ he Provider must submit the informed consent form for Secondary Uses of the Material to the HREC should the need arise for Secondary Use. This is specific to secondary uses related to the research project for which the materials will be used in accordance with the conditions stipulated in the MTA. This clause does not include the secondary use of materials into perpetuity. In addition, if it is impracticable or impossible to obtain re-consent from the donor, the HREC will make a considered determination and review and approve all secondary uses as indicated in clause 6 of the MTA.

\section{Dispute settlement}

That disputes arise during the course of and even after a research project has been finalised/terminated/completed is a reality. The processes with regard to dispute settlement in the SA MTA are multilayered, consisting of informal and then more formal processes. As a last resort, an action may be instituted in an SA court, unless the 
dispute is agreed by the parties to be resolved by arbitration in terms of a separate arbitration agreement (clause 11). Should any dispute arise and the jurisdiction be outside SA, local researchers, donors and institutions may not be able to afford to attend the proceedings. This requirement is also in keeping with standards prescribed by Western counterparts; e.g. in terms of its dispute resolution processes, UK Biobank specifically outlines that any unresolved dispute is to be mediated at the London Court of International Arbitration and that the language used will be English. ${ }^{[39]}$ It may be argued that arbitration proceedings weaken the dispute resolution process somewhat, in that such an arbitration process may occur outside SA. However, the parties must agree to an arbitration process being instituted. Should an agreement on this issue not be reached, an action may be instituted in an SA court.

\section{Conclusions}

The SA MTA, like most legal documents, is not perfect, but it does provide a framework that can serve as a safeguard for cross-border transfer of HBMs in the absence of chapter 8 regulations in this regard. Justice and fairness, two key ethical principles in research, are reinforced by the SA MTA. Furthermore, the SA MTA's provisions are entrenched in the fundamental principle of human dignity, a principle integral to health research ethics. SA is well known for taking the lead in protecting participants in research. ${ }^{[40]}$ The SA MTA is a fitting example of such a safeguard.

\section{Declaration. None.}

Acknowledgements. None

Author contributions. Equal co-authors: ML, AD, SM; editing and input: KB, AN, KM, PC-J, AO, NM, CP.

Funding. None.

Conflicts of interest. None.

1. World Medical Association. Declaration of Taipei on Ethical Considerations Regarding Health Databases and Biobanks. WMA, 2016. https://www.wma.net/policies-post/wma-declaration-oftaipei-on-ethical-considerations-regarding-health-databases-and-biobanks/ (accessed 27 October 2018).

2. South Africa. National Health Act 61 of 2003. https://www.gov.za/documents/national-health-act (accessed 8 March 2019).

3. South Africa. National Health Act 61 of 20013. Regulations: Import and export of human tissue, blood, blood products, cultured cells, stem cells, embryos, fetal tissue, zygotes and gametes. Governmen Gazette No. 35099, March 2012. Published under Government Notice R181. https://www.gov, za/documents/national-health-act-regulations-import-and-export-human-tissue-blood-blood products-0 (accessed 8 March 2019)

4. University of the Witwatersrand. The Human Research Ethics Committee Medical: Material Transfer Agreement for Human Biological Materials. 2018. https://www.wits.ac.za/media/wits-university/ research/documents/Wits\%20MTA\%202018.docx (accessed 22 January 2019).

5. Health Professions Council of South Africa. Guidelines for Good Practice in Health Care Professions General Ethical Guideline for Health Researchers. HPCSA, 2016 (Booklet 13). https://wwwhpcsa co za/Uploads/editor/UserFiles/downloads/conduct_ethics/Booklet\%2010 pdf (accessed 27 October co.za/

6. National Department of Health, South Africa. Ethics in Health Research: Principles, Processes and Structures. 2nd ed. 2015. https://www.commerce.uct.ac.za/Downloads/Ethics\%20in\%20Health\%20 Structures. 2nd ed. 2015. https://www.commerce.uct.ac.za/Dow
Research\%20Final\%20A\%20used.pdf (accessed 27 October 2018).

7. South Africa. National Health Act 61 of 2003. Material Transfer Agreement of Human Biological Materials. Government Gazette No. 41781: 719, 20 July 2018. https://www.gov.za/sites/default/ files/41781_gon719.pdf (accessed 27 October 2018).

8. Bennett AB, Streitz WD, Gacel RA. Specific issues with material transfer agreements. In: Krattige A, Mahoney RT, Nelsen L, et al., eds. Intellectual Property Management in Health and Agricultura Innovation: A Handbook of Best Practices. MIHR (Centre for the Management of Intellectual Property in Health Research and Development), PIPRA (Public Intellectual Property Resource for Agriculture), Oswaldo Cruz Foundation, and bioDevelopments-International Institute, 2007: Section 7: 697-717. http://www.iphandbook.org/handbook/resources/Publications/links/ipHandbook\%20Volume\%202. pdf (accessed 10 October 2018)

9. Sathar A, Dhai A, van der Linde S. Collaborative international research: Ethical and regulatory issue pertaining to human biological materials at a South African institutional research ethics committee. Dev World Bioeth 2013;14(3):150-157. https://doi.org/10.1111/dewb.12018
10. Moodley K, Sibanda N, February K, Rossouw T. 'It's my blood': Ethical complexities in the use, storage and export of biological samples: Perspectives from South African research participants. BMC Med Ethics 2014:15:4. https://doi.org/10.1186/1472-6939-15-4

11. Moodley K, Singh S. 'It's all about trust': Reflections of researchers on the complexity and controversy surrounding biobanking in South Africa. BMC Med Ethics 2016;7:57. https://doi.org/10.1186/s12910016-0140-2

12. Mahomed S, Behrens K, Slabbert M, Sanne I. Managing human tissue transfer across national boundaries - an approach from an institution in South Africa. Dev World Bioeth 2016;16(1):29-35. https://doi.org/10.1111/dewb.12080

13. Nienaber A. Consent to and authorization of the export and use of human biological specimens for future research - perspectives from three African countries. Comparative and International Law Journal of Southern Africa 2011;44(2):225-254. https://www.jstor.org/stable/23253098 (accessed 22 January 2019).

14. South Africa. Protection of Personal Information Act 4 of 2013. http://www.justice.gov.za/inforeg/ docs/InfoRegSA-POPIA-act2013-004.pdf (accessed 30 October 2018).

15. Bubela T, Guebert J, Mishra A. Use and misuse of material transfer agreements: Lessons in proportionality from research, repositories, and litigation. PLoS Biol 2015;13(2):e1002060. https://doi. org/10.1371/journal.pbio. 1002060

16. Caulfield T, Harmon SH, Joly Y. Open science versus commercialization: A modern research conflict? Genome Med 2012;4(2):17. https://doi.org/10.1186/gm316

17. Council for International Association of Medical Scientists. International Guidelines for Health-related Research Involving Humans. Geneva: CIOMS, 2016. https://cioms.ch/wp-content/uploads/2017/01/ WEB-CIOMS-EthicalGuidelines.pdf (accessed 30 October 2018)

18. Workmen's Compensation Commissioner v De Villiers 1949 1SA 474 (C)

19. Neethling J, Potgieter JM, Visser, JM. Law of Delict. 7th paperback E-edition. Durban: LexisNexis South Africa, 2014:69-70 and 158-159.

20. Beckmann J. University research ethics clearances: Safety nets, or a false sense of legal immunity? S Afr J High Educ 2017;31(3):6. https://doi.org/10.20853/31-3-1049

21. Weiss v. Solomon. [1989] A.Q. 312 (Sup. Ct.).

22. (A11/2014) [2014] ZAWCHC 157 (22 October 2014). http://www.saflii.org/za/cases/ZAWCHC/ 2014/157 (accessed 22 January 2019)

23. World Health Organization. Draft R\&D Blueprint MTA tool text, clauses 7 - 9. WHO, 2017. http:// www.who.int/blueprint/what/norms-standards/Draft-mta-tool.pdf?ua=1 (accessed 24 October 2018).

24. Medical Research Council, UK. Ethics series: Human tissue and biological samples for use in research: Operational and ethical guidelines: Ownership, custodianship and the gift relationship. London: MRC, 2015:8-9. http://www.mrc.ac.uk/research/facilities/regulatory-support-centre/human-tissue/ accessed 12 November 2018)

25. Yassin R, Lockhart N, del-Riego MG, et al. Custodianship as an ethical framework for biospecimenbased research. Cancer Epidemiol Biomarkers Prev 2010;19(4):1012-1015. https://doi. org/10.1158/1055-9965.EPI-10-0029

26. Verlinden M, Nys H, Ectors N, Huys I. Qualitative study on custodianship of human biological materials and data stored in biobanks. BMC Med Ethics 2016;17:15. https://doi.org/10.1186/s12910016-0098-0

27. Mahomed S. An ethico-legal framework for biobank research. UNISA College of Law, November 2018. http://www.sahivsoc2018.co.za/wp-content/uploads/2018/11/20B_Safia-Mahomed.pdf (accessed 8 March 2019).

28. Washington University v Catalona 490 F 3d 667 - Court of Appeals, 8th Circuit 2007. https:// openjurist.org/490/f3d/667/washington-university-v-j-catalona-md (accessed 22 January 2019).

29. Gibson SF. Washington University v Catalona: Determining ownership of genetic samples. Jurimetrics J 2008;48(2):167-191. https://www.jstor.org/stable/25767397?seq=1\#metadata_info_tab_contents 2008:48(2):167-191. hips:

30. Moore v Regents of the University of California 51 Cal. 3d 120;271 Cal. Rptr. 146; 793 P 2d 479. https://www.courtlistener.com/opinion/2608931/moore-v-regents-of-university-of-california/ (accessed 22 January 2019).

31. Baulig LT. Are there property rights in human tissue? J Lancaster Gen Hosp 2010;5(3):87-90. http:// www.jlgh.org/Past--Issues/Volume-5---Issue-3/Medico-Legal-Matters.aspx (accessed 22 January 2019).

2. Harmon A. Indian tribe wins fight to limit research of its DNA. New York Times, 22 April 2010. http:// archive.boston.com/news/education/k_12/articles/2010/04/22/arizona_state_settles_dna_case_with_ tribe/ (accessed 4 November 2018) (accessed 22 January 2019).

33. Piljak Estate v. Abraham, 2014 Ontario Superior Court of Justice 2893 (CanLII). http://www biodiritto. org/index.php/item/download/426 6b9a9df2b3ef17ffdfc4acae0c9de4e8 (accessed 22 January 2019).

4. Yearworth v North Bristol NHS Trust 2010 Queen's Bench. https://swarb.co.uk/yearworth-and-others$\mathrm{v}$-north-bristol-nhs-trust-ca-4-feb-2009/ (accessed 22 January 2019).

35. Troug RD, Kesselheim AS, Joffe S. Paying patients for their tissue: The legacy of Henrietta Lacks. Science 2012;337(6):37-38. https://moodle.epfl.ch/pluginfile.php/1479571/mod folder/content/0/ Paying_Patients_for_Their_Tissue-The_Legacy_of_Henrietta_Lacks_Science-2012-Truog. Paying_Patients_fo__Their_Tissue-The_Legacy__

36. Mahomed S, Nöthling-Slabbert M, Pepper MS. Ownership and human tissue - the legal conundrum: A response to Jordaan's critique. S Afr Med J 2017;107(3):196-198. https://doi.org/10.7196/SAMJ.2017. 1073.12062

37. South Africa. National Health Act 61 of 2003. Regulations: General control of human bodies, tissues, blood, blood products and gametes. Government Gazette No. 35099, March 2012. Published under Government Notice R180. http://www.samed.org.za/Filemanager/userfiles/REGULATIONS\%20 REGARDING\%20THE\%20GENERAL\%20CONTROL\%20OF\%20HUMAN\%20BODIES\%20 TISSUE\%20BLOOD....pdf (accessed 8 March 2019).

38. Ojamaa B. Return our boys' foreskins and pay, NGO told after 'secret' cut. 2018. https://www.thestar.co.ke/news/2018/07/21/return-our-boys-foreskin-and-pay-ngo-told-after-secret-cut_c1790189 (accessed 12 November 2018)

39. UK Biobank. Collaborator's MTA v1.3, 2017. http://www.ukbiobank.ac.uk/wp-content/ uploads/2011/03/20170519-Collaborator-MTA-for-website.pdf (accessed 12 November 2018).

10. Dhai A. The evolution of research participant protections in South Africa. S Afr Med J 2017;107(7):571572. https://doi.org/10.7196/SAMJ.2017.v107i7.12438 